\title{
Prevalence and correlates of carotid artery stenosis in a cohort of Sri Lankan ischaemic stroke patients
}

\author{
K. C. D. Mettananda ${ }^{1,2^{*} \dagger}$, M. D. P. Eshani ${ }^{1,3}$, L. M. Wettasinghe ${ }^{1,3}$, S. Somaratne ${ }^{2}$, Y. P. Nanayakkkara², \\ W. Sathkorala ${ }^{4}$, A. Upasena ${ }^{4}$, C. Sirigampola², P. M. Y. Tilakaratna ${ }^{3,5}$, A. Pathmeswaran ${ }^{6}$ and U. K. Ranawaka ${ }^{2,3,5+}$
}

\begin{abstract}
Background: Large artery atherosclerotic disease is an important cause of stroke, accounting for $15-46 \%$ of ischaemic strokes in population-based studies. Therefore, current guidelines from west recommend urgent carotid imaging in all ischaemic strokes or transient ischaemic attacks and referral for carotid endarterectomy. However, the clinical features and epidemiology of stroke in Asians are different from those in Caucasians and therefore the applicability of these recommendations to Asians is controversial. Data on the prevalence of carotid artery stenosis (CAS) among South Asian stroke patients is limited. Therefore, we sought to determine the prevalence and associated factors of significant CAS in a cohort of Sri Lankan patients with ischaemic stroke.
\end{abstract}

Methods: We prospectively studied all ischaemic stroke patients who underwent carotid doppler ultrasonography admitted to the stroke unit of a Sri Lankan tertiary care hospital over 5 years. We defined carotid stenosis as low $(<50 \%)$, moderate (50-69\%) or severe (70-99\%) or total-occlusion (100\%) by North American Symptomatic Trial Collaborators (NASCET) criteria. We identified the factors associated with CAS $\geq 50 \%$ and $\geq 70 \%$ by stepwise multiple logistic regression analysis.

Results: A total of 550 ischaemic stroke patients (326 (59.3\%) male, mean age was $58.9 \pm 10.2$ years) had carotid doppler ultrasonography. Of them, 528 (96.0\%) had low-grade, 12 (2.2\%) moderate and 7 (1.3\%) severe stenosis and 3 (0.5\%) had total occlusion. On multivariate logistic regression, age was associated with CAS $\geq 50 \%(O R 1.12, p=0.001)$ and $C A S \geq 70 \%$ (OR 1.14, $p=0.016$ ), but none of the other vascular risk factors studied (sex, hypertension, diabetes mellitus, smoking, past history of TIA, stroke or ischemic heart disease) showed significant associations.

Conclusions: Carotid stenosis is a minor cause of ischemic stroke in Sri Lankans compared to western populations with only $4.0 \%$ having CAS $\geq 50$ and $3.5 \%$ eligible for carotid endarterectomy. Our findings have implications for the management of acute strokes in Sri Lanka.

Keywords: Carotid stenosis, South Asians, Ischemic strokes, Prevalence, Risk-factors, Sri Lanka

\footnotetext{
*Correspondence: chamila@kln.ac.lk; chamilametta@hotmail.com

${ }^{\dagger}$ K. C. D. Mettananda and U. K. Ranawaka contributed equally to this work.

${ }^{1}$ Department of Pharmacology, Faculty of Medicine, University

of Kelaniya, Talagolla Road, Ragama, Sri Lanka

Full list of author information is available at the end of the article
}

(c) The Author(s) 2021. Open Access This article is licensed under a Creative Commons Attribution 4.0 International License, which permits use, sharing, adaptation, distribution and reproduction in any medium or format, as long as you give appropriate credit to the original author(s) and the source, provide a link to the Creative Commons licence, and indicate if changes were made. The images or other third party material in this article are included in the article's Creative Commons licence, unless indicated otherwise in a credit line to the material. If material is not included in the article's Creative Commons licence and your intended use is not permitted by statutory regulation or exceeds the permitted use, you will need to obtain permission directly from the copyright holder. To view a copy of this licence, visit http://creativecommons.org/licenses/by/4.0/. The Creative Commons Public Domain Dedication waiver (http://creativeco mmons.org/publicdomain/zero/1.0/) applies to the data made available in this article, unless otherwise stated in a credit line to the data. 


\section{Background}

Large artery atherosclerotic disease is an important cause of stroke, accounting for $15-46 \%$ of ischaemic strokes in population-based studies [1-5], and is considered the stroke subtype with the highest recurrence risk [6, 7]. Extracranial internal carotid artery stenosis (CAS) is the most important cause of large artery stroke [1]. Carotid endarterectomy (CEA) has been shown to reduce the relative risk of disabling stroke or death by $48 \%$ in patients with severe CAS [8-11] and by $27 \%$ in patients with moderate CAS $[8,9,12,13]$. Latest acute stroke management guidelines recommend referring all patients with ischaemic strokes/transient ischaemic attacks who are candidates for carotid intervention, for carotid imaging as soon as possible, preferably within $24 \mathrm{~h}$ [14-17]. However, the applicability of these recommendations in different populations depends on the local prevalence of CAS and their risk associations. Carotid artery stenosis (CAS) is known to be more associated with White patients and is less among Black or Asian patients [18]. However, data on the prevalence of CAS and its risk associations among South Asian stroke patients is limited. Therefore, we sought to study the prevalence and correlates of CAS in a cohort of Sri Lankan ischaemic stroke patients.

\section{Methods}

We prospectively studied all ischaemic stroke patients admitted to the stroke unit of the Colombo North Teaching Hospital (CNTH), Sri Lanka over 5 years (20142019); The Ragama stroke registry. The CNTH is a 1550-bed tertiary care hospital situated in the suburban city of Ragama, $18 \mathrm{~km}$ from the capital city of Colombo. $\mathrm{CNTH}$ is the only tertiary care hospital in the administrative district of Gampaha. Sri Lanka is divided into 25 administrative districts and Gampaha is the second-most populated district in the country, with $11.32 \%$ of the total population and a population density of $1711 / \mathrm{km} 2$. Gampaha has the whole spectrum of rural, semi-urban and urban populations. The Stroke Unit at the CNTH is the only stroke unit in the Gampaha district.

Data on demographics, vascular risk factors, stroke characteristics and outcome were recorded prospectively by trained investigators using an interviewer-administered questionnaire, supplemented by medical records. All ischemic stroke patients who underwent Carotid doppler ultrasonography were included in this study.

Carotid stenosis was defined as low $(<50 \%)$, moderate $(50-69 \%)$ or severe $(70-99 \%)$ or total-occlusion $(100 \%)$ by the percentage stenosis according to North American Symptomatic Carotid Endarterectomy Trial (NASCET) classification [10].

A total of 891 stroke patients were admitted to the stroke unit over the 5 years, and 765 (85.5\%) of them were ischaemic strokes. Of all patients with ischaemic strokes, 550 (71.9\%) had undergone carotid doppler studies as inpatients and were recruited for this study.

Data were analysed using IBM SPSS statistics version 22.0. Continuous variables were reported as means with standard deviation (SD), and categorical variables were reported as percentages. The significance level was set at $p<0.05$. Factors associated with CAS $\geq 50 \%$ and $\geq 70 \%$ were separately identified by stepwise multiple logistic regression analysis.

Ethical approval was obtained from the Ethics Review Committee of the Faculty of Medicine, University of Kelaniya, Sri Lanka. Informed written consent of the patients was obtained.

\section{Results}

A total of 550 patients with ischaemic stroke who underwent carotid doppler studies as in-patients at the stroke unit over the 5 year study period formed the study population. There were 326 (59.3\%) males, with a mean age of $58.9 \pm 10.2$ years. All have had brain CT or MRI scans done. Baseline characteristics and vascular risk factors of the study population are shown in Table 1.

Prevalence of CAS; 528 (96.0\%) had low degree (<50\%) stenosis, $12(2.2 \%)$ had moderate (50-69\%) stenosis, 7 (1.3\%) had severe (70-99\%) stenosis, and 3 (0.5\%) had total occlusion of the extracranial internal carotid artery

Table 1 Baseline characteristics and vascular risk factor profiles of the study population

Frequency

(\%)

$(n=550)$

\begin{tabular}{ll}
\hline Demographic characteristics & \\
Male sex & $326(59.3)$ \\
Age >60years & $293(53.3)$ \\
Ethnicity & \\
Sinhalese & $517(94.0)$ \\
Tamil & $14(2.5)$ \\
Muslim & $13(2.4)$ \\
Burgher & $5(0.9)$ \\
Chinese & $1(0.2)$ \\
Vascular risk factors & \\
Hypertension & $347(63.1)$ \\
Diabetes mellitus & $307(55.8)$ \\
Hyperlipidaemia & $169(30.7)$ \\
Current smoking & $137(24.9)$ \\
Previous IHDa & $99(18.0)$ \\
Previous stroke & $94(17.1)$ \\
Previous TIA & $48(8.7)$ \\
\hline
\end{tabular}

a $I H D$ ischaemic heart disease

${ }^{\mathrm{b}}$ TIA transient ischaemic attacks 
Table 2 Associations of vascular risk factors with different degrees of carotid artery stenosis

\begin{tabular}{|c|c|c|c|c|c|c|c|c|}
\hline & \multirow{2}{*}{$\begin{array}{l}<70 \% \text { CAS group } \\
n=540 \\
n,(\%)\end{array}$} & \multirow{2}{*}{$\begin{array}{l}\geq 70 \% \text { CAS } \\
\text { group } n=10 \\
n,(\%)\end{array}$} & \multicolumn{2}{|c|}{$\begin{array}{l}\text { Association with } \\
\geq 70 \% \text { CAS }\end{array}$} & \multirow{2}{*}{$\begin{array}{l}<50 \% \text { CAS group } \\
n=528 \\
n,(\%)\end{array}$} & \multirow{2}{*}{$\begin{array}{l}\geq 50 \% \text { CAS } \\
\text { group } n=22 \\
n,(\%)\end{array}$} & \multicolumn{2}{|c|}{$\begin{array}{l}\text { Association with } \\
\geq 50 \% \text { CAS }\end{array}$} \\
\hline & & & OR & $p^{*}$ & & & OR & $p^{*}$ \\
\hline Age (years) & & & 1.14 & 0.016 & & & 1.12 & 0.001 \\
\hline Male sex & $318(58.9)$ & $8(80.0)$ & 0.43 & 0.331 & $311(58.9)$ & $15(68.2)$ & 0.79 & 0.659 \\
\hline Hypertension & $342(63.8)$ & $5(50.0)$ & 0.68 & 0.583 & $335(63.4)$ & $12(54.5)$ & 0.71 & 0.493 \\
\hline Diabetes mellitus & $304(56.6)$ & $3(30.0)$ & 0.42 & 0.238 & 298(56.4) & $9(40.9)$ & 0.58 & 0.252 \\
\hline Hyperlipidaemia & 164(30.8) & $2(20.0)$ & 0.84 & 0.849 & 193(36.8) & $6(27.3)$ & 0.88 & 0.826 \\
\hline Smoking & $134(25.1)$ & $3(30.0)$ & 1.36 & 0.697 & 131(24.8) & $3(27.3)$ & 1.31 & 0.631 \\
\hline Previous TIA & $48(9)$ & $0(0)$ & 0.00 & 0.997 & $47(8.9)$ & $1(4.5)$ & 0.61 & 0.643 \\
\hline Previous stroke & $94(17.5)$ & $0(0.0)$ & 0.00 & 0.996 & $91(17.2)$ & $3(13.6)$ & 0.81 & 0.743 \\
\hline Previous IHD & $96(17.8)$ & $3(30.0)$ & 2.47 & 0.239 & $95(18.0)$ & $4(18.2)$ & 1.06 & 0.921 \\
\hline
\end{tabular}

TIA transient ischaemic attack, IHD ischaemic heart disease, CAS Carotid artery stenosis

${ }^{*}$ Adjusted for all the variables in the model

on the symptomatic side. CAS of $\geq 50 \%$ was seen in 22 (4.0\%) patients.

Associations of both CAS $\geq 50 \%$ and $C A S \geq 70 \%$ on stepwise multiple logistic regression analysis are shown in Table 2. Age was independently associated with both $\mathrm{CAS} \geq 50 \%$ (OR 1.12, $p=0.001$ ) and $\mathrm{CAS} \geq 70 \%$ (OR $1.14, p=0.016)$. The other vascular risk factors studied, i.e. male sex, hypertension, diabetes mellitus, smoking, past history of TIA, stroke or ischemic heart disease were not significantly associated with CAS.

\section{Discussion}

To our knowledge, this is the first study describing the prevalence and risk associations of CAS among Sri Lankan stroke patients. We observed low prevalence rates of significant carotid artery stenosis, with CAS $\geq 50 \%$ in only $4.0 \%, 70-99 \%$ in only $1.3 \%$ and total occlusion in $0.5 \%$. This finding has major implications in adopting the UK, European or American Stroke guidelines to Sri Lanka and possibly to South Asia.

Ethnic differences in stroke aetiologies are well recognised [19-22]. While western countries have more cardioembolic strokes (20-35\%), Asians have more atherosclerotic strokes (25-65\%). Prevalence of small-vessel disease is higher in Asians (prevalence 50\%) than in Caucasians (prevalence 20\%) [23]. Embolic strokes due to emboli originating from the heart or extracranial large arteries are common in Western populations, whereas small-vessel occlusion or intracranial atherosclerosis is more prevalent in Asians [23]. Whites have more extracranial carotid atherosclerosis [20, 24], whereas Asians have more intracranial atherosclerotic disease [22, 25, 26]; 54\% of ethnic South Asians living in Singapore [27] and $29.4 \%$ of Indian patients in the Hyderabad stroke registry [28] were reported to have intracranial large-artery disease. Among ischaemic stroke subtypes, lacunar strokes, which were once the commonest variety in Asians, are now declining. Emerging data suggest that large artery atherosclerosis and in particular that of intracranial vessels is the predominant aetiology in most Asian countries [21].

Studies of multi-ethnic populations have shown that whites have a higher prevalence of CAS than nonwhites [18, 24, 29-33]. Community prevalence of CAS in the USA is reported to be highest among native Americans (OR 1.3) and lowest in African Americans (OR 0.69) and Asians (OR 0.65) compared to Caucasians [32]. Prevalences of CAS $\geq 80 \%$ in a USA hospital-based study were, $9.2 \%$ in whites compared to $4.3 \%$ in Hispanics, $2.9 \%$ in blacks, and $2.8 \%$ in Asians [34]. Similarly, the prevalence of CAS $\geq 50 \%$ in a multi-ethnic population in the Netherlands, were 16\% among whites, $10 \%$ among blacks and $9 \%$ among Asians and the adjusted odds ratio of having CAS $\geq 50 \%$ in nonwhite populations compared to white populations was 0.44 [18]. Carotid atherosclerosis in a population-based study of Canada reported higher among Europeans $(0.75 \mathrm{~mm})$ than in South Asians $(0.72 \mathrm{~mm})$ and Chinese $(0.69 \mathrm{~mm})$ [31].

Low rates of extracranial CAS in Asian populations could be related to several reasons. The differential prevalence of vascular risk factors observed between Asian and white Caucasian populations is one. Risk factors known to be associated with extracranial CAS such as older age, smoking and hyperlipidaemia [35-37] are commoner among western populations [38-40], whereas factors associated with intracranial atherosclerosis such as diabetes mellitus and metabolic syndrome [35-37, 40] are more prevalent in Asians [41, 42]. Comparing our study with a contemporary study from the UK, our study 
had lower extracranial CAS $>50 \%$ (4.0\% vs $7.9 \%)$, patients were younger (mean age 58.9 vs 71.4 years) and had lower rates of smoking (25\% vs $35 \%$ ) and hyperlipidaemia (30\% vs 55\%) and higher prevalence of diabetes mellitus (56\% vs $24 \%$ ), mostly leading to a vascular phenotype favouring intracranial atherosclerosis [33].

Prevalence of severe CAS among our population (1.8\%) was even lower when compared with recent data from other South Asian countries. CAS $\geq 70 \%$ is reported in $10 \%$ of stroke patients from India [43] and 12\% from Pakistan [44]. The different prevalence rates may be partly due to methodological differences between studies. Compared to our study $(n=550)$, the study by Bharathykunisetty [43] was only 100 patients recruited over a one-year duration. We studied only extracranial internal carotid artery stenosis, but some studies have reported both extracranial and intracranial atherosclerosis which would naturally yield a higher rate of stenosis; e.g. Razzaq et al. reported carotid atherosclerosis in $22 \%$ of young stroke patients from Pakistan, but extracranial carotid stenosis was seen in only 7.9\% [45]. Furthermore, we studied only symptomatic stenoses, but some studies have included both symptomatic and asymptomatic stenoses in their analyses, e.g., Wasay et al. reported CAS of $\geq 70 \%$ in $12 \%$ of patients but only $7 \%$ were symptomatic [44]. Compared to older studies from South Asia, better medical care and risk factor management may have contributed to the low prevalence rate in our study. Sri Lanka is considered a role model in health development in a developing country and has consistently performed better than its South Asian neighbours in terms of health and social indicators, such as the Human Development Index, life expectancy at birth and female literacy rate [46]. It is, therefore, plausible that lower prevalence rates seen in our study compared to other South Asian countries may also be related to better vascular risk factor management in Sri Lanka.

We observed that significant CAS was associated with increasing age but not with sex or other common vascular risk factors (hypertension, diabetes, hyperlipidaemia, smoking, previous TIA/stroke). Tan et al. reported similar findings in their study of Taiwanese patients [26]. Other studies have noted CAS to be associated with risk factors such as male sex, smoking, diabetes mellitus, hypertension, hypercholesterolemia and past history of stroke $[33,35,43,47]$, but there is much variation in the associations reported between studies.

Strengths of our study include the large number of consecutive patients with ischaemic stroke studied in a single unit over a long period of 5 years, confirmation of ischaemic stroke with CT and/or MRI scanning in all patients, and prospective data collection minimizing recall bias and selection bias. However, some limitations need to be acknowledged. Only $72 \%$ of patients admitted with ischaemic stroke during the study period had carotid doppler assessments. Due to resource limitations, carotid doppler studies were not done in all patients during the hospital stay. Further, patients who were too ill to be transported to the Radiology department did not have doppler scanning. We have included data from all patients who had carotid doppler studies during the hospital stay.

However, our carotid imaging rate was much higher compared to in some Asian studies (38\%) [48], and comparable to some studies from more developed countries such as the USA (79\%) [24]. As the study was conducted over 5 years, carotid doppler studies were done by three different radiologists with more than 10years' experience, and therefore, some inter-observer variability in the assessment of the exact percentage of CAS is a possibility. However, since the patients were categorised into only 4 categories, $<50 \%, 50-69 \%, 70-99,100 \%$ the effect of this on final occlusions would be minimal. Our data are from hospital admissions in a single tertiary care centre and therefore may not be generalizable to the community at large. Furthermore, we reported only the prevalence of extracranial CAS, but the burden of undetected intracranial atherosclerosis is not reflected in our study.

\section{Conclusions}

We report the first data on CAS in Sri Lankan patients with ischaemic stroke. Clinically significant CAS of $\geq 50 \%$ and $70-99 \%$ is seen among 4.0 and $1.3 \%$ of Sri Lankan ischaemic stroke patients, respectively. These figures are much lower compared to Western data, and further research is needed to understand the reasons behind the low prevalence rates in our patients. Our findings have implications in the uptake of western guidelines on acute stroke management in Sri Lankan stroke patients. Costeffectiveness in urgent carotid imaging in all patients with TIA or stroke is questionable in Sri Lankans including South Asians and probably we need to adopt western guidelines with suitable amendments to suit local disease epidemiology.

\section{Abbreviations \\ CAS: Carotid artery stenosis; NASCET: North American Symptomatic Trial Collaborators; CEA: Carotid endarterectomy; CNTH: Colombo North Teaching Hospital.}

\section{Acknowledgements}

EMDP and WLM were supported by a research grant from the National Stroke Association of Sri Lanka.

\section{Authors' contributions}

Conception and design - UKR, CDM, PMYT. Acquisition of data - MDPE, LW, SS, YPN. Analysis and interpretation of data AP. Drafting the article or revising it critically for important intellectual content - CDM, UKR, Final approval of the 
version to be published - all. Agreement to be accountable for all aspects of the work - all.

\section{Funding}

None.

\section{Availability of data and materials}

The datasets used and/or analysed during the current study are available from the corresponding author on reasonable request.

\section{Declarations}

\section{Ethics approval and consent to participate}

Ethical approval was obtained from the Ethics committee of Faculty of Medicine, University of Kelaniya, Sri Lanka. All methods were carried out in accordance with relevant guidelines and regulations.

\section{Consent for publication}

Granted.

\section{Competing interests}

None.

\section{Author details}

'Department of Pharmacology, Faculty of Medicine, University of Kelaniya, Talagolla Road, Ragama, Sri Lanka. ${ }^{2}$ Stroke Unit, Colombo North Teaching Hospital, Ragama, Sri Lanka. ${ }^{3}$ Department of Medicine, Faculty of Medicine, University of Kelaniya, Ragama, Sri Lanka. ${ }^{4}$ Radiology Unit, North Colombo Teaching Hospital, Ragama, Sri Lanka. ${ }^{5}$ University Medical Unit, North Colombo Teaching Hospital, Ragama, Sri Lanka. ${ }^{6}$ Department of Public Health, Faculty of Medicine, University of Kelaniya, Ragama, Sri Lanka.

\section{Received: 13 January 2021 Accepted: 21 September 2021}

\section{Published online: 04 October 2021}

\section{References}

1. Cole JW. Large Artery Atherosclerotic Occlusive Disease. Continuum (Minneapolis, Minn). 2017;23:133-57.

2. Kolominsky-Rabas PL, Weber M, Gefeller O, Neundoerfer B, Heuschmann PU. Epidemiology of ischemic stroke subtypes according to TOAST criteria: incidence, recurrence, and long-term survival in ischemic stroke subtypes: a population-based study. Stroke. 2001;32:2735-40.

3. Smith WS, Lev MH, English JD, Camargo EC, Chou M, Johnston SC, et al. Significance of large vessel intracranial occlusion causing acute ischemic stroke and TIA. Stroke. 2009;40:3834-40.

4. Malhotra K, Gornbein J, Saver JL. Ischemic strokes due to large-vessel occlusions contribute disproportionately to stroke-related dependence and death: a review. Front Neurol. 2017;8:651

5. Marulanda-Londoño E, Chaturvedi S. Stroke due to large vessel atherosclerosis: five new things. Neurol Clin Pract. 2016;6:252-8.

6. Lovett JK, Coull AJ, Rothwell PM. Early risk of recurrence by subtype of ischemic stroke in population-based incidence studies. Neurology. 2004:62:569-73

7. Elnady HM, Mohammed GF, Elhewag HK, Mohamed MK, Borai A. Risk factors for early and late recurrent ischemic strokes. Egypt J Neurol Psychiatry Neurosurg. 2020;56:56.

8. Barnett HJM, Taylor DW, Haynes RB, Sackett DL, Peerless SJ, Ferguson GG, et al. Beneficial effect of carotid endarterectomy in symptomatic patients with high-grade carotid stenosis. N Engl J Med. 1991;325:445-53.

9. Group ECSTC. MRC European carotid surgery trial: interim results for symptomatic patients with severe (70-99\%) or with mild (0-29\%) carotid stenosis. European Carotid Surgery Trialists' Collaborative Group. Lancet. 1991;337:1235-43.

10. Barnett HJ, Taylor DW, Eliasziw M, Fox AJ, Ferguson GG, Haynes RB, et al. Benefit of carotid endarterectomy in patients with symptomatic moderate or severe stenosis. North American symptomatic carotid Endarterectomy trial collaborators. N Engl J Med. 1998;339:1415-25.
11. Rothwell PM, Warlow CP. Prediction of benefit from carotid endar terectomy in individual patients: a risk-modelling study. Lancet. 1999:353:2105-10.

12. Orrapin S, Rerkasem K. Carotid endarterectomy for symptomatic carotid stenosis. Cochrane Database Syst Rev. 2017;6:Cd001081.

13. Cina CS, Clase CM, Haynes RB. Carotid endarterectomy for symptomatic carotid stenosis. Cochrane Database Syst Rev. 2000(2):Cd001081.

14. Stroke and transient ischaemic attack in over 16s: diagnosis and initial management: National Institute for Health and Clinical Excellence 2019 [updated May 2019].

15. Powers WJ, Rabinstein AA, Ackerson T, Adeoye OM, Bambakidis NC, Becker K, et al. Guidelines for the early Management of Patients with Acute Ischemic Stroke: 2019 update to the 2018 guidelines for the early Management of Acute Ischemic Stroke: a guideline for healthcare professionals from the American Heart Association/American Stroke Association. Stroke. 2019:50:e344-418.

16. The European Stroke Organisation Executive C, the ESOWC. Guidelines for Management of Ischaemic Stroke and Transient Ischaemic Attack 2008. Cerebrovasc Dis. 2008;25:457-507.

17. Lindsay P, Furie KL, Davis SM, Donnan GA, Norrving B. World Stroke Organization global stroke services guidelines and action plan. Int J Stroke. 2014;9(Suppl A100):4-13.

18. Wolma J, Nederkoorn PJ, Goossens A, Vergouwen MD, van Schaik IN, Vermeulen M. Ethnicity a risk factor? The relation between ethnicity and large- and small-vessel disease in White people, black people, and Asians within a hospital-based population. Eur J Neurol. 2009;16:522-7.

19. Bang OY. Considerations When Subtyping Ischemic Stroke in Asian Patients. J Clin Neurol. 2016;12:129-36.

20. Bang OY, Saver JL, Liebeskind DS, Pineda S, Yun SW, Ovbiagele B. Impact of metabolic syndrome on distribution of cervicocephalic atherosclerosis: data from a diverse race-ethnic group. J Neurol Sci. 2009;284:40-5

21. Mehndiratta MM, Khan M, Mehndiratta P, Wasay M. Stroke in Asia: geographical variations and temporal trends. J Neurol Neurosurg Psychiatry. 2014;85:1308-12.

22. White $H$, Boden-Albala B, Wang C, Elkind MS, Rundek T, Wright CB, et al. Ischemic stroke subtype incidence among whites, blacks, and Hispanics: the northern Manhattan study. Circulation. 2005;111:1327-31.

23. Kim BJ, Kim JS. Ischemic stroke subtype classification: an Asian viewpoint. J Stroke. 2014;16:8-17.

24. Flaherty ML, Kissela B, Khoury JC, Alwell K, Moomaw CJ, Woo D, et al. Carotid artery stenosis as a cause of stroke. Neuroepidemiology. 2013;40:36-41.

25. Feldmann E, Daneault N, Kwan E, Ho KJ, Pessin MS, Langenberg P, et al. Chinese-white differences in the distribution of occlusive cerebrovascular disease. Neurology. 1990;40:1540.

26. Tan TY, Chang KC, Liou CW, Schminke U. Prevalence of carotid artery stenosis in Taiwanese patients with one ischemic stroke. J Clin Ultrasound. 2005:33:1-4.

27. De Silva DA, Woon FP, Lee MP, Chen CP, Chang HM, Wong MC. South Asian patients with ischemic stroke: intracranial large arteries are the predominant site of disease. Stroke. 2007;38:2592-4.

28. Kaul S, Alladi S, Jabeen SA, Bandaru VCSSR, Ankem U, Mekala S, et al. Intracranial atherosclerosis is the Most common stroke subtype: ten-year data from Hyderabad stroke registry (India). Ann Indian Acad Neurol. 2018;21:209-13.

29. Sacco RL, Roberts JK, Boden-Albala B, Gu Q, Lin IF, Kargman DE, et al. Race-ethnicity and determinants of carotid atherosclerosis in a multiethnic population. The Northern Manhattan Stroke Study. Stroke. 1997:28:929-35.

30. Mackinnon AD, Jerrard-Dunne P, Porteous L, Markus HS. Carotid intima-media thickness is greater but carotid plaque prevalence is lower in black compared with white subjects. AJNR Am J Neuroradiol. 2010;31:1951-5.

31. Anand SS, Yusuf S, Vuksan V, Devanesen S, Teo KK, Montague PA, et al. Differences in risk factors, atherosclerosis, and cardiovascular disease between ethnic groups in Canada: the study of health assessment and risk in ethnic groups (SHARE). Lancet. 2000;356:279-84.

32. Rockman CB, Hoang H, Guo Y, Maldonado TS, Jacobowitz GR, Talishinskiy T, et al. The prevalence of carotid artery stenosis varies significantly by race. J Vasc Surg. 2013;57:327-37. 
33. Cheng SF, Brown MM, Simister RJ, Richards T. Contemporary prevalence of carotid stenosis in patients presenting with ischaemic stroke. Br J Surg. 2019;106:872-8.

34. Wang MY, Mimran R, Mohit A, Lavine SD, Giannotta S. Carotid stenosis in a multiethnic population. J Stroke Cerebrovasc Dis. 2000;9:64-9.

35. Kim JS, Nah HW, Park SM, Kim SK, Cho KH, Lee J, et al. Risk factors and stroke mechanisms in atherosclerotic stroke: intracranial compared with extracranial and anterior compared with posterior circulation disease. Stroke. 2012:43:3313-8.

36. Li Y, Cai Y, Zhao M, Sun J. Risk factors between intracranial-extracranial atherosclerosis and anterior-posterior circulation stroke in ischaemic stroke. Neurol Res. 2017;39:30-5.

37. Ji R, Pan Y, Yan H, Zhang R, Liu G, Wang P, et al. Current smoking is associated with extracranial carotid atherosclerotic stenosis but not with intracranial large artery disease. BMC Neurol. 2017;17:120.

38. Ueshima H, Sekikawa A, Miura K, Turin TC, Takashima N, Kita Y, et al. Cardiovascular disease and risk factors in Asia: a selected review. Circulation. 2008;118:2702-9.

39. Hyun KK, Huxley RR, Arima H, Woo J, Lam TH, Ueshima H, et al. A comparative analysis of risk factors and stroke risk for Asian and nonAsian men: the Asia Pacific cohort studies collaboration. Int J Stroke. 2013;8:606-11.

40. Chen X, Zhou L, Zhang Y, Yi D, Liu L, Rao W, et al. Risk factors of stroke in Western and Asian countries: a systematic review and Meta-analysis of prospective cohort studies. BMC Public Health. 2014;14:776.

41. Bank IEM, Gijsberts CM, Teng T-HK, Benson L, Sim D, Yeo PSD, et al. Prevalence and clinical significance of diabetes in Asian versus White patients with heart failure. JACC Heart Fail. 2017;5:14-24.
42. Lee JWR, Brancati FL, Yeh H-C. Trends in the prevalence of type 2 diabetes in Asians versus whites: results from the United States National Health Interview Survey, 1997-2008. Diabetes Care. 2011;34:353-7.

43. Bharathikunisetty S, Senthilnathan R, Arjundas D, Ayyar SSK, Kumar S. Prevalence and risk factors of carotid artery stenosis in ischaemic stroke patients- a cross-sectional study in a tertiary care hospital. Int J Adv Res. 2019;7:958-64.

44. Wasay M, Azeemuddin M, Masroor I, Sajjad Z, Ahmed R, Khealani BA, et al. Frequency and outcome of carotid atheromatous disease in patients with stroke in Pakistan. Stroke. 2009;40:708-12.

45. Razzaq AA, Khan BA, Jadoon CK, Baig SM. Carotid Doppler ultrasonography in young stroke patients. J Pak Med Assoc. 1999;49:97-9.

46. Ranawaka UK. Stroke Care in Sri Lanka: the way we were, the way we are, and the way forward. J Stroke Med. 2018;1:45-50.

47. Mathiesen EB, Joakimsen O, Bonaa KH. Prevalence of and risk factors associated with carotid artery stenosis: the Tromso study. Cerebrovasc Dis. 2001;12:44-51.

48. Razzaq AA, Khan BA, Baig SM. Ischemic stroke in young adults of South Asia. J Pak Med Assoc. 2002;52:417-22

\section{Publisher's Note}

Springer Nature remains neutral with regard to jurisdictional claims in published maps and institutional affiliations.
Ready to submit your research? Choose BMC and benefit from:

- fast, convenient online submission

- thorough peer review by experienced researchers in your field

- rapid publication on acceptance

- support for research data, including large and complex data types

- gold Open Access which fosters wider collaboration and increased citations

- maximum visibility for your research: over $100 \mathrm{M}$ website views per year

At BMC, research is always in progress.

Learn more biomedcentral.com/submissions 